\title{
Design of models for the tokenization of electric power industry basing on the blockchain technology
}

\author{
Andrew Varnavskiy \\ Financial University under the \\ Government of the RF, \\ Leningradsky Prospekt 49, \\ Moscow, Russia \\ Email: AVVarnavskiy@fa.ru \\ Vladislav Trubnikov \\ Financial University under the \\ Government of the RF \\ Leningradsky Prospekt 49, \\ Moscow, Russia \\ Email: vladtrubnikov95@gmail.com
}

\author{
Ulia Gruzina \\ Financial University under the \\ Government of the RF \\ Leningradsky Prospekt 49, \\ Moscow, Russia \\ Email: ymgruzina@fa.ru \\ Anastasia Buryakova \\ Financial University under the \\ Government of the RF \\ Leningradsky Prospekt 49, \\ Moscow, Russia \\ Email: AOBuryakova@fa.ru
}

\author{
Artur Rot \\ Wroclaw University \\ of Economics, \\ ul. Komandorska 118/120, \\ 53-345 Wroclaw, Poland \\ Email: artur.rot@ue.wroc.pl \\ Ekaterina Sebechenko \\ Financial University under the \\ Government of the RF \\ Leningradsky Prospekt 49, \\ Moscow, Russia \\ Email: EVSebechenko@fa.ru
}

\begin{abstract}
The problem of implementing modern technologies into the electric power industry is quite relevant in the world. The article considers the models of decentralized platforms providing services for energy distribution and trade, their main advantages and disadvantages. The basic principles of tokenization were developed, which allow optimizing of the energy systems and concentration of the crowd funding process for the construction of new generation facilities.
\end{abstract}

\section{INTRODUCTION}

$\mathrm{N}$ owadays, an entire "ecosystem" of companies has been formed around the concept of a distributed ledger, which build their work using internal accounting units. Thanks to the technology of the distributed registry, it becomes possible to optimize the generating and trading process of power capacities, which ensures a high demand from companies from all over the world.

The aim of the work is to identify the most optimal model for the operation of the decentralized energy platform to increase the efficiency of the generation and distribution of electric power.

In order to systematize the obtained data, we use methods of retrospective, current and prospective analysis and synthesis of theoretical and practical material.

The peculiarity of blockchain technology lies in the fact that the network ledger is updated every time as a transaction occurs. Suppliers and consumers determine the variables of a given transaction by allocating the specific parameters, address of sender, sum and amount of energy, as well as other necessary information, after which the variables are

The material has been prepared with the results of studies carried out at the expense of funds provided under the grant of the Bank Santander. combined with detailed information on other transactions conducted during the same period of time to create a new block data. If any information relating to a particular transaction is subsequently changed as a result of unauthorized interference or due to data transmission errors, the algorithm will report an error.

There are allocated characteristics among the merits of the blockchain technology: reduction of transaction costs; ensuring maximum transparency of operations; reducing the overall complexity of transactions; storage of accurate data on all transactions performed. The shortcomings of the technology are mainly due to the lack of the necessary infrastructure and regulatory component: an undefined status of tokens (special kind of virtual currency that represent an asset or utility) - accounting units of the system, which are used, among other things, to purchase goods; lack of a regulatory framework for dispute resolution in some countries of the world; possible technical problems and failures in the initial stages of the technology introduction; complete loss of control over the tokens (system currency) in circulation in the case of cyberattacks. From the point of view of the electricity market, it should be noted that all energy transactions can be accurately recorded for certain suppliers and consumers. Controlling the distributed and consumed energy will inevitably lead to its most effective use, and also enable producers to plan generation in advance. These features become more sustainable under the system of Smart Grid operations. The platform of blockchain-options trading can provide a necessary level of automation using the smart contracts, which will reduce the costs and helps to directly connect consumers and suppliers of energy. 
The platform also has its own investment foundation for suppliers, which goes as an addition, but can help form a system of trust and discounts, especially for large buyers.

Despite having some automated functions, our platform cannot be classified as a Multi-agent system, because it still has to have a lot administrative control over the course of its work.

\section{RELATED WORK}

During the study, a special attention was paid to the documentation of already existing energy projects: Greeneum [1], Suncontract [2], Grid + [3], Impact PPA [3], Power Ledger [4], Energo Labs [5], Exergy project [6], Enerchain [7], WePower [8]. A thorough analysis of the energy tokenization (the process of converting rights to real world assets into a digital token on a blockchain) proposed by the projects made it possible to identify the main principles on which the energy trade platform should be built. The provisions of the EY [9], PWC [10], Deloitte [11] reports allowed to look at the possibilities of using blockchain technology in the electric power industry. Confirmation of ownership and trading in emission allowances for pollutants are truly promising and original ideas.

Moreover, the experience of some foreign researchers was studied and analyzed. For example, Basden J., Cottrell M. in the work "How utilities are using blockchain to modernize the grid" [12] surely indicate that the blockchain is a reliable, inexpensive way to conduct and control transactions without a central generation unit of power. According to the authors, the blockchain will promote the development of renewable energy microgrid. Alternatively, Thomas Morstyn, Niall Farrell, Sarah J. Darby and Malcolm D. McCulloch in their article "Using peer-to-peer energy-trading platforms to incentivize prosumers to form federated power plants" [13] drew attention to the prospects of introducing intelligent solutions and energy management systems to ensure universal and safe access to energy. Technical problems and recent achievements, identified in the work "Blockchain Challenges and Opportunities" [14] Zheng Z. et al. also found their reflection in our article.

During the analysis of the market we used the experience of Russian scientists. The following works were considered: Bogdanova ED, Valieva LG "Cryptocurrency and energy" [15], Veselov FV, Khokhlov A. "Internet of Energy: how distributed energy will affect safety, prices for electricity and ecology" [16], Lyalkov IM "Management of financial risks in companies of the fuel and energy complex" [17], etc.

\section{ANALYSIS OF EXISTING BLOCKCHAIN MODELS IN THE ENERGY SECTOR}

The tokens issued during the ICO can perform a variety of functions - payment for goods, works, services provided by the company; various discounts and bonuses; means of payment; system access keys; confirmation of ownership of an asset or a normal means of attracting financing, etc. For example, a token is the accounting unit of a system whose properties depend solely on how the community will use it. Tokens can be secured with property, have a constant inflation rate, the company can also provide some monetary policy. The number of tokens produced by projects is also not limited, which allows creating different models that meet the requirements of the platform. Different models of tokenization of a number of energy projects were analyzed in the course of the study.

WePower is a platform that allows producers of renewable sources of energy to tokenize and sell generated power. Joining the platform, the manufacturer receives the number of tokens, and get equally supplied energy. $1 \mathrm{kWh}$ is equal to 1 token. Each energy supplier, connected to the platform, organizes an auction for the sale of tokenized energy. Consumers who own WePower tokens have priority access to auctions. The amount of energy they acquire will depend on the number of WePower tokens that they have. The auction starts with the lowest, base price $(1 \mathrm{kWh}=1 \mathrm{WPR})$. Holders of WPR tokens have extended access for the first 48 hours, after which the non-sold energy is offered to all participants of the platform. Current and historical energy prices are fixed and displayed in the application, which allows participants to focus on the market situation.

An important point is that WePower energy suppliers get the right to sell tokens to consumers without real deliveries at the time of the transaction, because a token is in form of obligation of the supplier to provide a certain amount of energy in the future. At the same time, suppliers with generation facilities and connected to the platform can receive a fee in WePower tokens or fiat money at the time of the transaction by giving energy.

In addition to the indicated advantages, the above models also have significant drawbacks. Thus, speculation on the exchange rate of coins of platforms is not ruled out. The offer of the token will depend wholly and entirely on the number of users providing and purchasing energy. The more suppliers, the more coins and the lower the price in conditions of weak demand. However, in the case of a very limited supply and high demand, attempts of fraud in the market cannot be brushed away, when profits will be used by suppliers for speculative purposes.

In order to consider more complex models, it is necessary to have a general idea of the operation of the power grid. The existing power system assumes the following stages of the process of bringing energy from the producer to the recipients: generation, transmission, distribution and retail. Generation, subsequently, is the production of energy by large producers of all types of electricity: hydrocarbon, nuclear, hydroelectric, etc. Recently, wind and solar farms has started to gain popularity. Transmission is the movement of electricity over long distances, usually "from generators" to "distributors". Distribution - the process of electricity 
transmission from high voltage networks to end users. "Distributors" work with low-voltage electric lines, which are connected to households or enterprises. The last stage is the stage of trade and will affect the changes caused by decentralization.

Here you can use a purely market-based instrument - a forward contract. Forward - an agreement by which one party (in our case the supplier) undertakes to transfer the goods (energy) to another party (buyer) in a specific contract, and the buyer agrees to accept and pay this asset on time. In the case of the energy market, forward contracts would be more reliable, since the supplier would receive a guarantee that all the energy produced will be realized, and the consumer would not have doubts about the sudden rise in prices. It would be possible to prevent part of the attempt to avoid speculation. However, such arguments will not always be appropriate.

It is necessary to pay special attention to the fact that a strong fluctuation of prices often occurs when tokens are not provided with any real goods. Confirmation of this thesis is the first model with one token, where a part of the coins has not actually been backed up by energy from the moment of entering the stock exchange. Tokens passed into the category of purely speculative instruments. The model with two tokens is specifically designed to eliminate this drawback by using various monetization mechanisms.

Power Ledger. The market flexibility of the ecosystem is designed to support the model with tokens performing the functions reflected in Table I.

The meaning of tokenization lies not only in assigning certain information to the accounting units to rationalize the distribution of energy, but also in the formation of fair prices. Some number of provisions are fixed in the process of supplying energy: volume, source (renewable / nonrenewable), geographical location of generating capacities, etc. These criteria are forming the basis of the price. That is, the token in this case is not a mean of calculation, but only a marker that helps the community to determine the price. Thanks to the use of smart contracts, it is possible to unite suppliers and consumers, minimizing the costs of both parties. Specificity of the tokenization model is described in the accompanying document "Exergy Business".

Based on the description of technology, we can distinguish the following functions of the internal accounting unit:

- identification of each physical operation (creation, transmission, storage, consumption of energy);

- ensuring the ownership of the main product of the project - energy;

- ensuring confidentiality and security of the main transactions;

- differentiation of generation types by the location of generating units and other significant and important characteristics.
TABLE I.

"Power LEDGER" TOKENIZATION MODEL

\begin{tabular}{|l|l|}
\hline \multicolumn{1}{|c|}{ POWR } & \multicolumn{2}{|c|}{ Sparkz } \\
\hline $\begin{array}{l}\text { 1. Traded on the stock exchange; } \\
\text { 2. Required to access the } \\
\text { platform; }\end{array}$ & $\begin{array}{l}\text { 1. Issued in return for POWR } \\
\text { through Smart Bond; } \\
\text { 2. Unit of energy cost in local } \\
\text { markets around the world; }\end{array}$ \\
$\begin{array}{l}\text { 3. Guarantees ownership of a } \\
\text { renewable energy asset; }\end{array}$ & $\begin{array}{l}\text { 3. Can be exchanged for cash; } \\
\text { 4. Charged to suppliers of } \\
\text { renewable energy as a reward } \\
\text { for loyalty; }\end{array}$
\end{tabular}

The description of the model from a technological point of view suggests that Exergy is going to ICO offering two tokens. One will be used only for internal purposes, and the second will be used to attract additional funding and new participants.

Of all the projects reviewed, five ICOs have already taken place. The Grid + energy trading platform following the PreICO results, which ended in July 2017, managed to attract \$ 45.076 million (Table II). Investments attracted by the WePower platform amounted to 40 million US dollars. The planned amount was collected in one day, ICO was stopped ahead of schedule. The Power Ledger project in September 2017 attracted \$ 13.23 million, Suncontract - \$ 2.5 million, EnergoLabs - \$2.2 million. So, the most successful strategies for attracting investments are Grid + and WePower solutions. Prior to joining the ICO, the companies already had agreements with energy companies, could present the tested technological solutions and conducted an active marketing policy.

Thus, analyzing the efficiency of blockchain technology on the market sites, it is worth taking into account both the direct advantages of applying the technology for energy exchange and the business plans of new companies, because the attraction of financing was also due to the issuance of digital accounting units of the system.

TABLE II.

THE VOLUME OF FINANCING ATTRACTED BY THE PROJECTS IN THE SECTOR OF POWER SUPPLY

\begin{tabular}{|l|l|l|l|}
\hline Project & $\begin{array}{l}\text { Stage } \\
\text { (ICO/Pre- } \\
\text { ICO) }\end{array}$ & $\begin{array}{l}\text { Date of } \\
\text { closing ICO }\end{array}$ & $\begin{array}{l}\text { The volume of } \\
\text { attracted financing, } \\
\text { thousands USD }\end{array}$ \\
\hline Suncontract & Pre-ICO & 28.07 .2017 & 2501 \\
\hline Grid+ & Pre-ICO & 30.11 .2017 & 45076 \\
\hline Power Ledger & ICO & 08.09 .2017 & 13232 \\
\hline EnergoLabs & ICO & 15.08 .2017 & 2228 \\
\hline WePower & ICO & 02.02 .2018 & 40000 \\
\hline
\end{tabular}

The general model of the considered energy decentralized platforms is indicated in Fig. 1. 


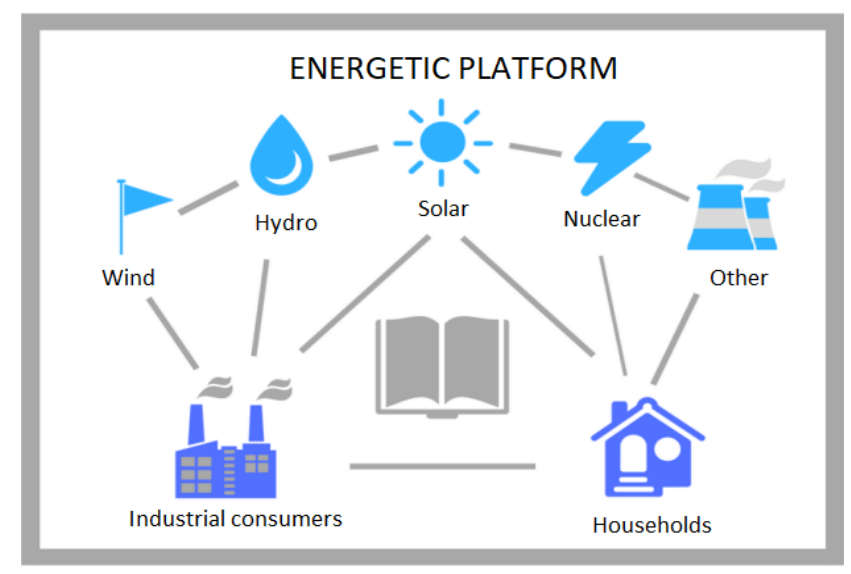

Fig. 1 Model of the decentralized energy area

Despite the advantages of a platform based on blockchain technology, it is still difficult to talk about the effectiveness of its work in terms of comparing costs and financial results, since none of the projects has been fully implemented. Nevertheless, theoretically the benefits to suppliers and consumers are undeniable. Elimination of intermediaries and introduction of $\mathrm{P} 2 \mathrm{P}$ transactions will inevitably lead to a reduction in energy prices under the conditions of high competition. It is worth noting the simplicity of the issue and sale of coins in the market as an investment tool. In ICO, all interested users can participate in the project development. Consumers will receive tokens, which can later be exchanged for electricity, investors after placing the coin on the exchange will be able to sell it at a market price. With a competent approach to the organization of a trading power market, it becomes possible to substantially optimize the work of the industry as a whole.

\section{The Main Characteristics OF THE ENERGY PLATFORM MODEL}

An integrated tokenization scheme was developed without the use of derivative financial instruments based on the analysis of models with two interconnected tokens, presented on the market (Fig. 2).

This scheme provides for six steps:

\section{Step 1}

At the initial stage, consumers / investors purchase an external token No. 1 equal to a certain amount of energy $\mathrm{X}$ $\mathrm{kWh}$ per ICO. The received money is sent to the project fund for further development of the platform, team reward, marketing, etc. At the same time, it is necessary to envisage the accrual of an internal token No. 2 to the accounts of consumers in exchange for a fiat currency. This need arises as a result of the fact that the number of external tokens will decrease with time due to them being burned out after the conclusion of transactions for the supply of energy.

The suppliers of energy receive their portion of tokens by signing agreement with the administration of the platform.
Later on they will appear on the consumers' wallets and exchange and eventually burned out.

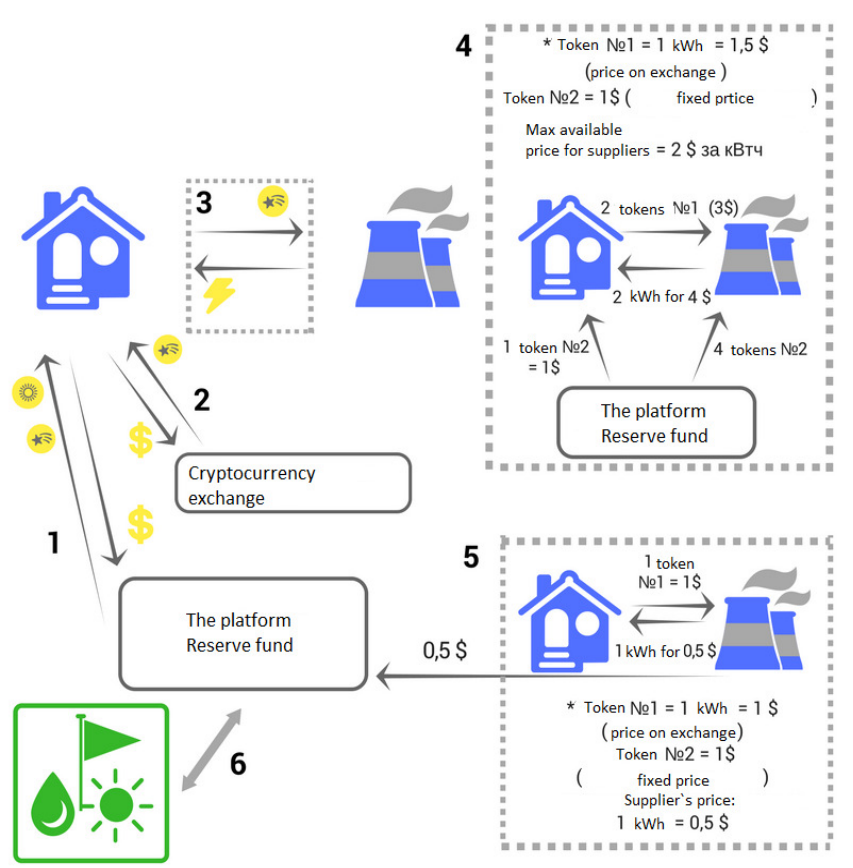

Fig. 2 Energy tokenization scheme

\section{Step 2}

Exit to the exchange is provided only for the external accounting unit - token No. 1. It is assumed that the price of the coin will grow due to an increase in demand and a constant reduction in their quantity in circulation. Thanks to this, energy suppliers will be able to receive compensation that allows them to compensate for energy generation costs.

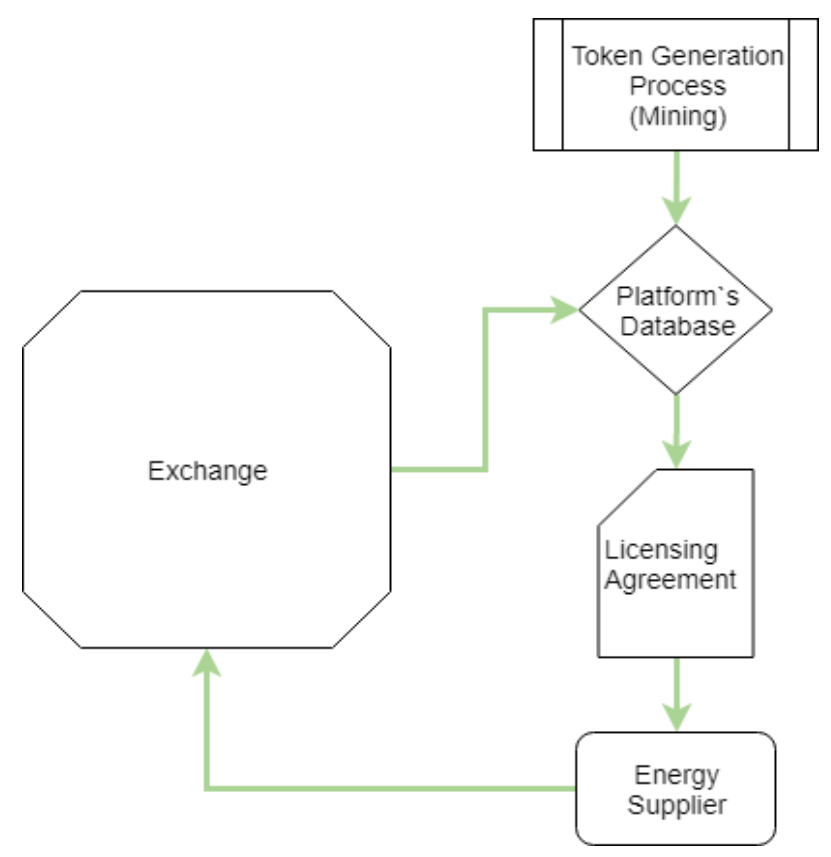

Fig.3 Token Generation process 


\section{Step 3}

Before users completely switch to transactions using token No. 2, consumers will use tokens№1 to purchase energy, but it is clear that the exchange in internal tokens is more convenient. Thus, the token №1 turns into a purely market instrument, backed by the right to purchase energy. In the market there can be two situations: 1 - the exchange price of the token No. 1 will be higher than the maximum possible price of supply and 2 - the exchange price will be lower than the prices set by the supplier.

\section{*Step 4}

If the price of the token No. 1 turns out to be lower than the prices set by the supplier, the consumer will receive compensated overpaid funds in tokens № 2. For example, if the token №1 at the exchange price of \$ 1 will give the right to purchase $1 \mathrm{kWh}$, and the supplier will be able to supply the required amount of energy only at a price of $\$ 2$, the consumer will be paid compensation in the amount of 1 US dollar equal to 1 internal token. But this situation is not so feasible. Presumably, the price of the token at the time of placement should be several percent higher than the market price, and further growth in the exchange rate should be supported not only by burning, but by an increase in demand for a constantly rising price of an asset.

\section{*Step 5}

The situation in which the price of the token No. 1 exceeds the price of suppliers, will be taken as the base one. Consumers will be able to use the guaranteed right to supply energy or refund, and suppliers will sell products at affordable prices. The greater the difference between the price of supply and demand, the greater the percentage of remuneration received by suppliers and the greater the amount of funds used to replenish the project's reserve fund.

However, it should be noted that such mechanism will take place until all tokens № 1 are eliminated. The technical token No. 2, which the whole platform should go over in time, will be equivalent to the national currency, which means that the system will operate according to a purely market mechanism, where demand balances the offer. In the future, new placements can be conducted to attract additional funding.

\section{Step 6}

The formation of the reserve fund will not only support the operation of the platform, but also reinvest the profits received for the construction of new generation facilities. Financing the construction of new stations will help increase the energy suppliers connected to the platform. The use of smart contracts to conclude transactions and the growth of the energy potential of the entire system will lead to the creation of the best terms of trade at low prices.

Thus, the model with two tokens was recognized as the most effective on the basis of the analysis of decentralized companies which provide services for energy distribution and trade. It allows to distinguish between trading on the exchange (coin/national currency) and intra-system trade (coin/energy). This approach also excludes the possibility of speculation, because each platform user can exchange a token only for energy. At the same time, minimization of risks occurs due to the formation of a reserve fund, which can be used in the emergency: a sharp increase in the costs of production of a supplier or a sudden drop in the solvency of consumers. The difference between the price of supply and demand will be offset by the resources accumulated by the system.

\section{CONCLUSION}

Thus, the following perspectives of the blockchain technology in the supply of electric power were identified the analysis of the Russian electricity market:

1. The optimization of the functioning of power systems.

2. Development of renewable energy sources by attracting additional financing through the ICO for the construction of energy generation facilities.

The analysis of the existing energy blockchain projects allowed us to identify the two most successful investment strategies - Grid + and WePower. The key factors were the signed agreements with energy companies, the availability of tested technological solutions and active marketing policy. However, it is still difficult to estimate the effectiveness of the projects reviewed in terms of comparing costs and financial results, since they are not fully implemented at the moment. Nevertheless, theoretically the benefits to suppliers and consumers are undeniable. It is established that the liquidation of intermediaries and introduction of $\mathrm{P} 2 \mathrm{P}$ transactions will inevitably lead to a reduction in energy prices under the conditions of high competition.

\section{REFERENCES}

[1] Official site of Greeneum project, White paper, https://www.greeneum.net/ greeneum-whitepaper/

[2] Official site of Suncontract project, White paper, https://suncontract.org/tokensale/res/whitepaper.pdf
Official site of Grid+ project, White paper,

[3] Official site of Grid+ project, White paper,
https://gridplus.io/assets/Gridwhitepaper.pdf

[4] Official site Impact PPA project, White paper, https://www.impactppa.com/wp-content/uploads/2018/03/ImpactPPA _ WP_v1.2WEB.pdf

[5] Official site of Power Ledger project, White paper, https://powerledger.io/media/Power-Ledger-Whitepaper-v8.pdf

[6] Official site of Energo Labs project, White paper, http://www.energolabs.com/

[7] Description of the Enerchain project, https://enerchain.ponton.de/

[8] Official site WePower project, White paper, https://drive.google.com/file/d/0B_OW_EddXO5RWWFVQjJGZXp QT3c/view

[9] EY, Overview of the Electricity Industry http://ru.investinrussia.com/data/file/EY-power-market-russia2018.pdf [In Russian].

[10] PwC, Use cases for blockchain technology in Energy \& Commodity trading - 2017, https://www.pwc.com/gx/en/industries/assets/ blockchain-technology-in-energy.pdf [Accessed 08.03.2018].

[11] Deloitte, Blockchain applications in energy trading - 2016, https://www2.deloitte.com/global/en/pages/energy-and- 
resources/articles/role-of-blockchain-in-the-energy-and-resourcesindustry.html [Accessed 28.04. 2018].

[12] J. Basden, M. Cottrell, How utilities are using blockchain to modernize the grid, Harvard Business Review, 2017.

[13] T. Morstyn, et al., Using peer-to-peer energy-trading platforms to incentivize prosumers to form federated power plants, Nature Energy, T. 3, No. 2. - C. 94, 2018.

[14] Z. Zheng et al., Blockchain challenges and opportunities: A survey, Work Pap., 2016.

[15] E.D. Bogdanova, L.G. Valieva, "Cryptocurrency and energy, Problems, prospects and tendencies of innovative science development", Collected articles of international academic and research conference - 2017, pp. 63-67 [In Russian].

[16] F.V. Veselov, A. Khokhlov, Internet of Energy: how distributed energy will affect safety, prices for electricity and ecology, Russian version of the information resource Forbes, section "Business", October 18, 2017 [In Russian].

[17] I.M. Lyalkov, "Management of financial risks in companies of the fuel and energy complex", Vestnik of the Russian Economic University. G.V. Plekhanov. Introduction. The way to science No. 1 (17), 2017, pp. 93-100 [In Russian].

[18] Official site of the system operator of the Unified Energy Network of Russia. Ensuring the long-term development of the EEC, http://soups.ru/index.php?id=future

[19] A.A. Burdin, Prerequisites for the Sustainable Development of the Electric Power Industry of Tatarstan, Synergy of Sciences No. 10., 2017, pp. 41-45, [In Russian].
[20] Exergy project Technical Whitepaper, https://exergy.energy/wpcontent/uploads/2017/12/Exergy-Whitepaper-v8.pdf

[21] MarketLab, Metallgesellschaft https://market-lab.org/kejsmetallgesellschaft

[22] U.S. Commodity futures trading commission, https://www.cftc.gov/About/MissionResponsibilities/index.htm/

[23] A.M. Rudkevich, M.C. Caramanis, E.A. Goldis, L. Xiaoguang, P.A. Ruiz, "Tabors R.D. Financial Transmission Rights in Changing Power Networks", Proceedings of Hawaii International Conference on System Sciences, No. 49, 2016, pp. 2326-2334.

[24] Arstechnica, Bitcoin's insane energy consumption, explained, https://arstechnica.com/tech-policy/2017/12/bitcoins-insane-energyconsumption-explained/

[25] M. Kindy, A. Divine, A Blockchain Reputation System For Determining Good Market Actors, https://medium.com/toplblog/divine-a-blockchain-reputation-system-for-determining-goodmarket-actors-7c47a0308ae8/

[26] T. Dickerson, M. Herlihy, P. Gazzillo, E. Koskinen, "Adding Concurrency to Smart Contracts, Computer Science" Distributed, Parallel, and Cluster Computing, Cornell University Library, https://arxiv.org/abs/1702.04467

[27] M.J. Mamontova, "Blockchain and opportunities of its implementation in energy, Information technology in science, management, social sphere and medicine: collected scientific proceedings of IV International scientific conference, December 5-8 2017, Tomsk, pp. 417-419 [In Russian]. 